\title{
Onychomadesis associated with chemotherapy: case report and mini literature review
}

This article was published in the following Dove Press journal:

Drug Design, Development and Therapy

14 August 2017

Number of times this article has been viewed

Ang $\mathrm{Li}^{1,2, *}$

Yanqiong $\mathrm{Li}^{1,3, *}$

Lingzhi Ge ${ }^{4}$

Ping $\mathrm{Li}^{1,3}$

Wenfei $\mathrm{Li}^{\prime}$

'Department of Dermatology, Qianfoshan Hospital, Shandong University, Jinan, People's Republic of China; ${ }^{2}$ Department of Clinical Medicine, Queen Mary School, Medical School, Nanchang University, Nanchang, People's Republic of China; ${ }^{3}$ Department of Clinical Medicine, Taishan Medical college, Tai'an, People's Republic of China; ${ }^{4}$ Department of Dermatology, Affiliated First Hospital of Taishan Medical college, Tai'an, People's Republic of China

*These authors contributed equally to this work
Correspondence: Wenfei Li Department of Dermatology, Qianfoshan Hospital, Shandong University, 16766 Jing-Shi Road, Jinan 2500 I4, People's

Republic of China

$\mathrm{Tel}+86$ I $379 \mid 126639$

Fax +86 53I 8296 7II4

Email Iwf888026@I63.com

\begin{abstract}
The side effects of chemotherapy drugs have increased in recent years, and some side effects can lead to onychomadesis. A 72-year-old woman who was diagnosed with an invasive ductal carcinoma of the right breast underwent a modified radical mastectomy in April 2015, followed by chemotherapy with capecitabine and nanoparticle albumin-bound paclitaxel (nab-paclitaxel). Subsequently, the patient experienced palmoplantar redness, pain, onycholysis, a transparent serous exudate, and onychomadesis. The chemotherapy was discontinued, and the patient was treated with oral vitamin B6, a polymyxin ointment, and a high-energy red light. The palmoplantar redness and pain were alleviated after 1 month. However, although her fingernails improved, dysesthesia symptoms remained, and all her toenails exhibited defects or deformities at a 24-month follow-up. The symptoms of this disorder should be recognized by dermatologists.
\end{abstract}

Keywords: capecitabine and nab-paclitaxel, side effects, onychomadesis loss of nail

\section{Introduction}

With new treatment strategies improving the treatment outcomes of cancer, ${ }^{1}$ an increasing number of chemotherapy drugs such as capecitabine (Roche, Shanghai, People's Republic of China) and nanoparticle albumin-bound paclitaxel (nab-paclitaxel) (Fresenius Kabi USA, LLC., MelrosePark, IL, USA) have been applied in clinical practice. Capecitabine has proven activity against several types of cancers, ${ }^{2}$ especially for breast and colon cancers. Nab-paclitaxel is a combination of paclitaxel and an albumin preparation, and paclitaxel is one of several cytoskeletal medications used to treat several types of cancer. Chemotherapy drugs such as capecitabine and nab-paclitaxel often have clinical side effects including hand-foot syndrome (HFS), acute paronychia, exudative hyponychial dermatitis, neutropenia, and hyperbilirubinemia.

Here, we describe a case of specific onychomadesis of all the toenails of a woman after she was treated with capecitabine and nab-paclitaxel. To the best of our knowledge, only five patients with onychomadesis associated with chemotherapy have been described in the English literature. ${ }^{3-6}$ Our patient had special clinical characteristics, and these features differed from those reported previously in the literature. This study was approved by Qianfoshan Hospital, Shandong University, and written informed consent has been provided by the patient to have the case details and any accompanying images published.

\section{Case report}

A 72-year-old woman who was diagnosed with an invasive ductal carcinoma of the right breast underwent a modified radical mastectomy in April 2015, followed by chemotherapy with $1,500 \mathrm{mg}$ of oral capecitabine (Xeloda Roche, Shanghai, 

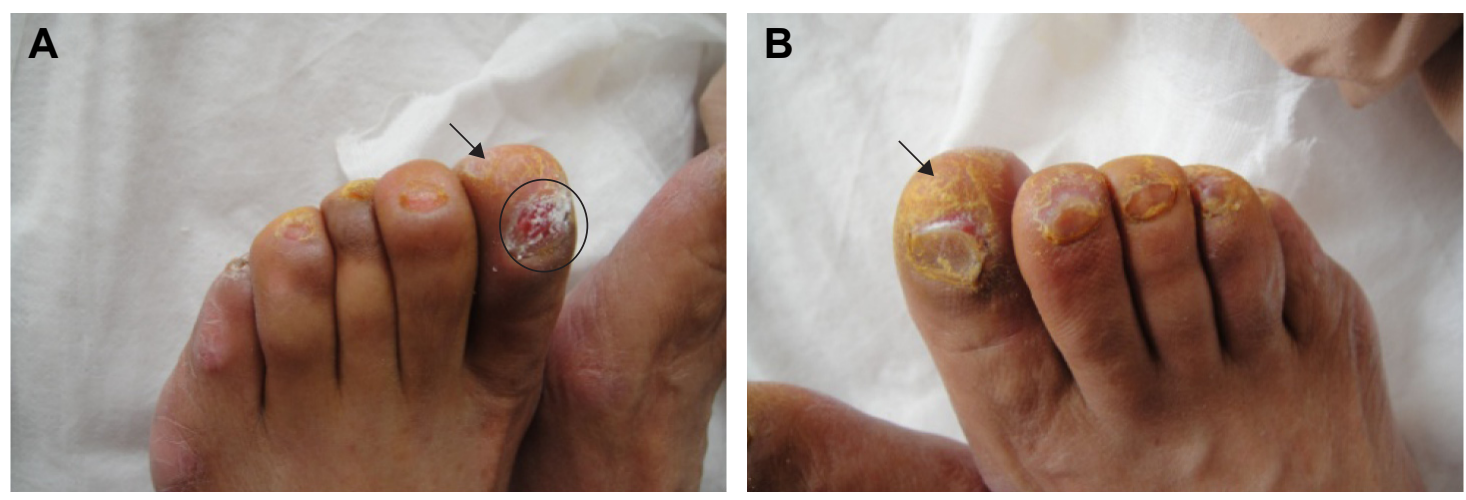

Figure I Subungual hyperkeratosis (arrow) (A, B), onycholysis, onychomadesis, and a transparent serous exudate emanating from the toenail bed (circle) (A).

People's Republic of China) twice daily for 2 weeks at 3-week intervals and $300 \mathrm{mg}$ of intravenous nab-paclitaxel every 3 weeks. The patient noticed dysesthesia and desquamation of her hands and feet, and thinning toenails after 1 month of chemotherapy. Three months later (1 week after the fourth round of chemotherapy), she visited our department while exhibiting palmoplantar redness, pain, onycholysis, a transparent serous exudate, and onychomadesis.

Examination of the patient revealed toenail changes including subungual hyperkeratosis, onycholysis, onychomadesis, and a transparent serous exudate emanating from all the nail beds (Figure 1). Her hands had desquamation and redness, and fingernail changes included dark pigmentations, Beau's lines, and subungual hyperkeratosis (Figure 2). The patient also complained of significant pain in the heels of her feet. In addition, numbness and dysesthesia of the hands and feet were noticed. Her dorsalis pedis pulse was normal, and a fungal microscopic exam was negative. The patient suffered from hypertension for 3 years, and she underwent coronary artery stenting in 2012. She was not diabetic, and she denied taking any drugs except aspirin and lovastatin.
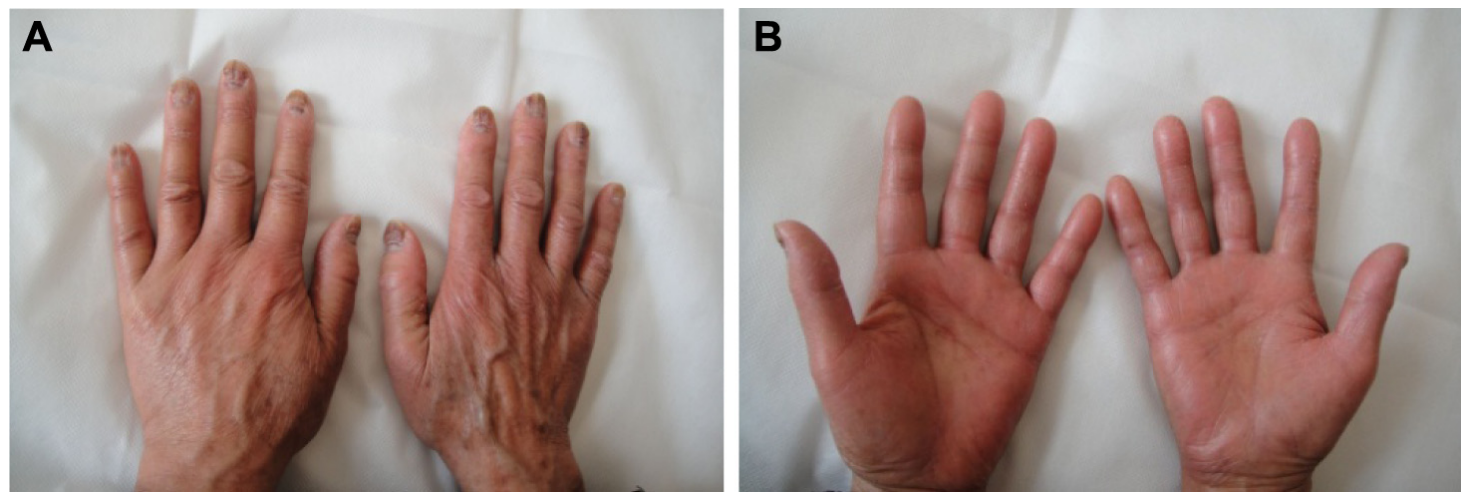

Figure 2 The patient's hands became desquamated and red (B). Fingernail changes included dark pigmentations, Beau's lines, and subungual hyperkeratosis (A). 

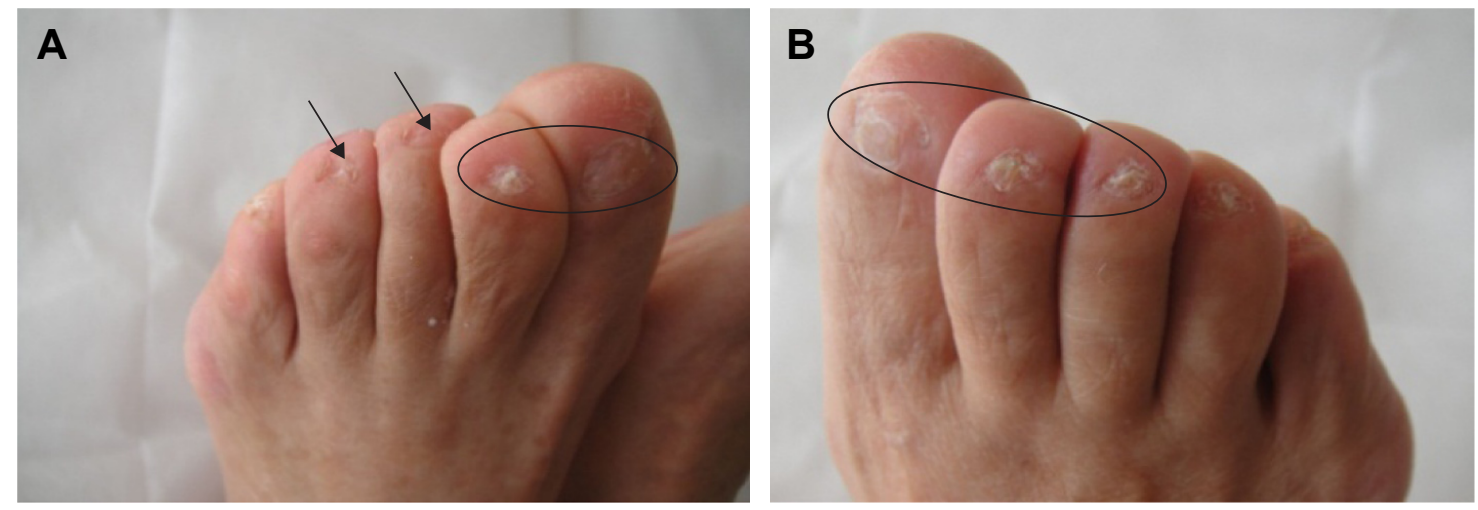

Figure 3 Dysesthesia symptoms remained, and all the toenails exhibited defects (arrow) (A) or deformities (circle) (A, B) at a 24-month follow-up.

increases in chemotherapy drug doses, her nail condition worsened. Additionally, her fingernail changes included dark pigmentation, Beau's lines, and trachyonychia. The nail changes that our patient presented with in this case study are rare. The severe toenail changes of grade 3 nail toxicity and HFS were compatible with grade 3 according to the National Cancer Institute Common Toxicity Criteria.

Our patient did not have a history of onychomycosis, pemphigus vulgaris, critical illness, or other conditions, and her fungal examination test was negative; thus, her onychomadesis was associated with the chemotherapeutic agents. The mechanism underlying onychomadesis from chemotherapy is not well understood, although several mechanisms have been proposed. ${ }^{7}$ Studies have shown that systemic chemotherapy may arrest mitotic activity in the nail matrix and the nail, resulting in nail separation and shedding. ${ }^{89}$ The spectrum of possible causes of onychomadesis, for example, Beau's lines, onycholysis, and shedding, is related to the weak or strong mitotic arresting activity of chemotherapy.

Although her onychomycosis was associated with capecitabine and nab-paclitaxel chemotherapy, we believe that capecitabine was probably responsible for the nail pathology, in consideration of previous cases. The HFS of our patient was compatible with grade 3 . In association with mitotane, HFS was originally described in $1974 .{ }^{10}$ Patients with HFS may experience a well-demarcated plaque, palmoplantar dysesthesia, and burning pain. There are some reports of HFS or nail toxicity due to chemotherapy, but reports of the simultaneous occurrence of onychomadesis and HFS are rare.

Even after many years of reports related to these side effects, there has been little information regarding effective treatments or prevention. ${ }^{11,12}$ Our patient was administered a high-energy red light after wound cleaning in the first week, while being given oral vitamin B6 and polymyxin ointment. High-energy red light can repair damaged tissue and has anti-inflammatory and analgesic activities. Exudation in the nail bed disappeared after 6 days. The significant pain symptoms were alleviated after receiving high-energy red light therapy for 1 month. Although her fingernails improved, dysesthesia symptoms remained, and all her toenails exhibited defects or deformities at a 24-month follow-up.
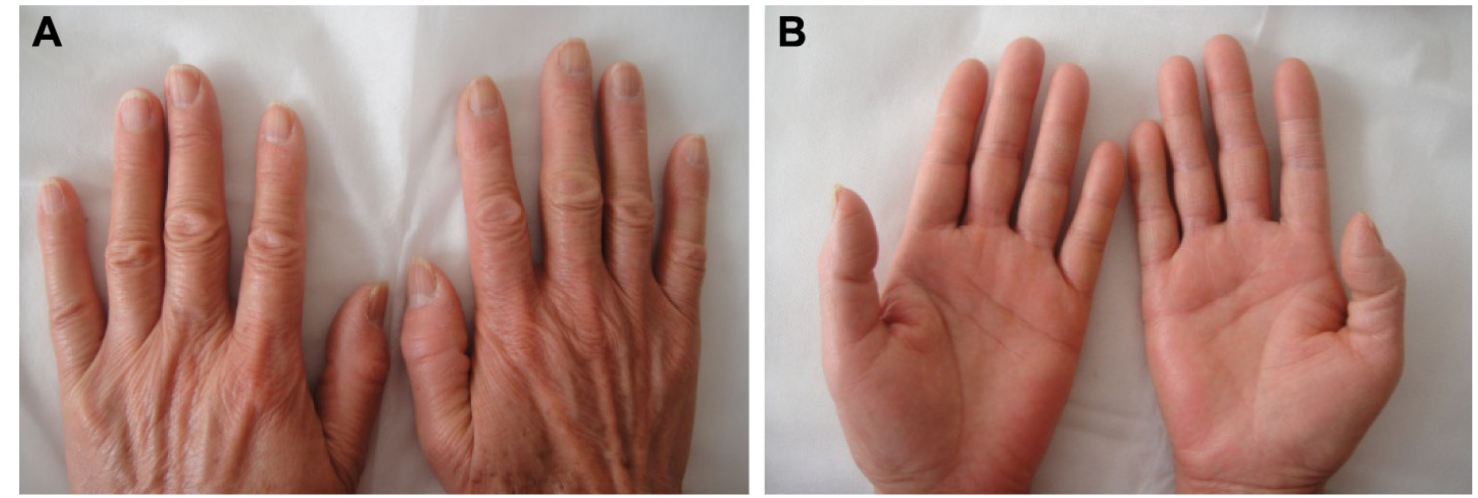

Figure 4 The patient's hands returned to normal (B). Fingernail changes improved at a 24-month follow-up (A). 
Table I Comparison of the literature on cases of chemotherapeutic agents that induced nail changes

\begin{tabular}{|c|c|c|c|c|c|}
\hline Case & Study & $\begin{array}{l}\text { Age (years)/ } \\
\text { gender }\end{array}$ & Primary disease & $\begin{array}{l}\text { Chemotherapeutic } \\
\text { agents }\end{array}$ & Nail changes \\
\hline 1 & $\begin{array}{l}\text { Kochupillai et al, }{ }^{3} \\
1983\end{array}$ & $36 / M$ & Hodgkin's disease & COPP & Onychomadesis \\
\hline 2 & $\begin{array}{l}\text { Kochupillai et al, } \\
\text { I } 983\end{array}$ & $27 / M$ & $\begin{array}{l}\text { Non-Hodgkin's } \\
\text { lymphoma }\end{array}$ & BACOP & $\begin{array}{l}\text { Onychomadesis. All nails had loosened and } \\
\text { dropped off }\end{array}$ \\
\hline 3 & $\begin{array}{l}\text { Cetin et al, } \\
1998\end{array}$ & $28 / F$ & $\begin{array}{l}\text { Acute myeloid } \\
\text { leukemia }\end{array}$ & $\begin{array}{l}\text { Adriamycin, cytosine } \\
\text { Arabinoside, Etoposide }\end{array}$ & $\begin{array}{l}\text { Onychomadesis. Nail grooves in all fingernails, } \\
\text { shedding of the nails. No change in color }\end{array}$ \\
\hline 4 & Chen et $a l,{ }^{5} 200 \mathrm{l}$ & $72 / F$ & Breast cancer & Capecitabine & Onychomadesis, leuconychia and onycholysis \\
\hline 5 & $\begin{array}{l}\text { Vaccaro et al, } \\
2008\end{array}$ & $69 / \mathrm{M}$ & Gastric cancer & Capecitabine & $\begin{array}{l}\text { HFS, onycholysis, onychomadesis. Periungual } \\
\text { pyogenic granuloma-like lesions, Beau's lines }\end{array}$ \\
\hline
\end{tabular}

Abbreviations: COPP, cyclophosphamide, vincristine, procarbazine, prednisolone; BACOP, bleomycin, adriamycin, cyclophosphamide, vincristine, prednisolone; HFS, hand-foot syndrome.

\section{Acknowledgments}

We would like to thank Drs Furen Zhang, Hong Liu, and Baoqi Yang in Shandong Provincial Hospital for Skin Diseases, Shandong University, for their help. This study was supported by the grant from Natural Science Foundation of Shandong (No Y2008C160 and No ZR2011HL056).

\section{Disclosure}

The authors report no conflicts of interest in this work.

\section{References}

1. Rashad N, Abdel-Rahman O. Differential clinical pharmacology of rolapitant in delayed chemotherapy-induced nausea and vomiting (CINV). Drug Des Devel Ther. 2017;11:947-954.

2. van Pelt-Sprangers MJ, Geijteman EC, Alsma J, et al. Oromandibular dystonia: a serious side effect of capecitabine. BMC Cancer. 2015;15:115.

3. Kochupillai V, Prabhu M, Bhide NK. Cancer chemotherapy and nail loss (onychomadesis). Acta Haematol. 1983;70(2):137.

4. Cetin M, Utas S, Unal A, et al. Shedding of the nails due to chemotherapy (onychomadesis). J Eur Acad Dermatol Venereol. 1998;11(2):193-194.
5. Chen GY, Chen YH, Hsu MM, et al. Onychomadesis and onycholysis associated with capecitabine. Br J Dermatol. 2001;145(3):521-522.

6. Vaccaro M, Barbuzza O, Guarneri F, et al. Nail and periungual toxicity following capecitabine therapy. Br J Clin Pharmacol. 2008;66(2): 325-326.

7. Hardin J, Haber RM. Onychomadesis: literature review. Br J Dermatol. 2015;172(3):592-596.

8. Hussain S, Anderson DN, Salvatti ME, et al. Onycholysis as a complication of systemic chemotherapy: report of five cases associated with prolonged weekly paclitaxel therapy and review of the literature. Cancer. 2000;88(10):2367-2371.

9. Maino KL, Norwood C, Stashower ME. Onycholysis with the appearance of a "sunset" secondary to capecitabine. Cutis. 2003;72(3):234-236.

10. Zuehlke RL. Erythematous eruption of the palms and soles associated with mitotane therapy. Dermatologica. 1974;148(2):90-92.

11. Scotte F, Banu E, Medioni J, et al. Matched case-control phase 2 study to evaluate the use of a frozen sock to prevent docetaxel-induced onycholysis and cutaneous toxicity of the foot. Cancer. 2008;112(7): $1625-1631$.

12. Macedo LT, Lima JP, dos Santos LV, et al. Prevention strategies for chemotherapy-induced hand-foot syndrome: a systematic review and meta-analysis of prospective randomised trials. Support Care Cancer. 2014;22(6):1585-1593.
Drug Design, Development and Therapy

\section{Publish your work in this journal}

Drug Design, Development and Therapy is an international, peerreviewed open-access journal that spans the spectrum of drug design and development through to clinical applications. Clinical outcomes, patient safety, and programs for the development and effective, safe, and sustained use of medicines are the features of the journal, which

\section{Dovepress}

has also been accepted for indexing on PubMed Central. The manuscript management system is completely online and includes a very quick and fair peer-review system, which is all easy to use. Visit $\mathrm{http}: / /$ www.dovepress.com/testimonials.php to read real quotes from published authors. 